3 McDonald V, Higgins I, Wood LG, et al. Multidimensional assessment and tailored interventions for COPD: respiratory utopia or common sense? Thorax 2013; 68: 691-694.

4 Han MK, Agusti A, Calverley PM, et al. Chronic obstructive pulmonary disease phenotypes: the future of COPD. Am J Respir Crit Care Med 2010; 182: 598-604.

5 Celli BR, Cote CG, Marín JM, et al. The body-mass index, airflow obstruction, dyspnea, and exercise capacity index in chronic obstructive pulmonary disease. N Engl J Med 2004; 350: 1005-1012.

6 Soler-Cataluña JJ, Martínez-García MA, Sánchez L, et al. Severe exacerbations and BODE index: two independent risk factors for death in male COPD patients. Respir Med 2009; 103: 692-699.

7 Agustí A, Calverley PMA, Celli B, et al. Characterisation of COPD heterogeneity in the ECLIPSE cohort. Respir Res 2010; 11: 122

8 Jones PW, Harding G, Berry P, et al. Development and first validation of the COPD Assessment Test. Eur Respir J 2009; 34: 648-654.

9 Van der Molen T, Willemse BWM, Schokker S, et al. Development, validity and responsiveness of the clinical COPD questionnaire. Health Qual Life Outcomes 2003; 1: 13.

10 Agustí A, Soler JJ, Molina J, et al. Is the CAT questionnaire sensitive to changes in health status in patients with severe COPD exacerbations? COPD 2012; 9: 492-498.

11 Miravitlles M, García-Sidro P, Fernández-Nistal A, et al. Course of COPD assessment test (CAT) and clinical COPD questionnaire (CCQ) scores during recovery from exacerbations of chronic obstructive pulmonary disease. Health Qual Life Outcomes 2013; 11: 147.

12 Kon SSC, Canavan JL, Jones SE, et al. Minimum clinically important difference for the COPD Assessment Test: a prospective analysis. Lancet Respir Med 2014; 2: 195-203.

13 Kocks JWH, Tuinenga MG, Uil SM, et al. Health status measurement in COPD: the minimal clinically important difference of the clinical COPD questionnaire. Respir Res 2006; 7: 62.

14 Miravitlles M, Soler-Cataluña JJ, Calle M, et al. Spanish COPD guidelines (GesEPOC). Pharmacological treatment of stable COPD. Arch Bronconeumol 2012; 48: 247-257.

\title{
Rhinovirus infection in young children is associated with elevated airway TSLP levels
}

To the Editor:

Rhinovirus wheezing illnesses during early childhood are strongly linked with development of asthma later in life [1]. Indeed, rhinovirus infection in the first 3 years of life is associated with an almost 10-fold increase in risk for asthma at age 6 years [1]. The exact mechanism by which rhinovirus elicits a proasthmatic propensity in young children is largely unknown, but is purportedly related to a viral-induced T-helper cell (Th)2 airway inflammatory response [2]. Interestingly, the discovery of interactions between epithelial innate immunity and adaptive allergic responses has unveiled new potential links between rhinovirus and asthma. Of particular interest is the epithelial-derived cytokine thymic stromal lymphopoietin (TSLP), which is considered a "master Th2 cytokine" because it primes the differentiation of naive T0 cells into Th2 lymphocytes via activation of antigen presenting cells [3]. TSLP is induced by rhinovirus infection or by exposure to double stranded (ds)RNA (viral surrogate) in the lungs of allergic mice [4], and in human bronchial epithelial cells (HBEC) [5]. Together, these data suggest that TSLP may be the missing link between innate antiviral epithelial immunity and the Th2 immune response characteristic of asthma.

This cross-sectional preliminary study aimed to investigate whether rhinovirus infections that occur naturally during the first 3 years of life are associated with elevated airway TSLP levels and enhanced Th2 responses, which may potentially facilitate the establishment of rhinovirus-induced pro-asthmatic changes during early childhood. We measured nasal airway TSLP, Th2 cytokines and antiviral responses in nasal washes obtained from newborns, infants and toddlers ( $\leqslant 3$ years) with PCR-confirmed acute rhinovirus infection $(n=71)$ relative to age-matched subjects without detectable virus using the PCR panel $(n=54)$. Nasal airway secretions were collected from children aged $\leqslant 3$ years seen in our medical centre (from February to December 2013) at the onset of acute respiratory illnesses by nasal saline lavage. The median (interquartile range) age of subjects was $0.58(0.15-0.83)$ years in the control group and $0.99(0.48-1.65)$ years in the rhinovirus group. There were no significant differences in the baseline demographic characteristics of the study groups, including ethnicity and sex. Nasal samples were analysed by a viral multiplex PCR kit (Luminex, TX, USA) for 14 targets used for clinical purposes in our institution according 
to the manufacturer's recommended protocol. Nasal airway protein levels of TSLP, interleukin (IL)-4, IL-13, IL-12 (p70), and interferon (IFN)- $\gamma$ were measured using a commercially available multiplex magnetic bead immunoassay (Millipore, MA, USA). Demographics and clinical information were obtained by electronic medical record review. This study was approved by the Institutional Review Board of the Children's National Medical Center, Washington, DC, USA.

Our results identified that young children with rhinovirus infection had higher mean \pm SE nasal TSLP levels compared with age-matched subjects without any identifiable virus $\left(16.7 \pm 1.2 \mathrm{pg} \cdot \mathrm{mL}^{-1}\right.$ versus $5.5 \pm 0.9 \mathrm{pg} \cdot \mathrm{mL}^{-1} ; \mathrm{p}<0.01$ ) (fig. 1a). Multivariate linear regression models identified that the association between rhinovirus infection and TSLP protein level (OR 8.25 (95\% CI 5.02-11.48); p<0.001) was independent of sex, gestational age at birth and race/ethnicity. To explore if acute rhinovirus infection is also linked to enhanced nasal secretion of Th2 cytokines we measured protein levels of IL-4 and IL-13 in the same study subjects. Figures $1 \mathrm{~b}$ and $\mathrm{c}$ show that young children with naturally occurring rhinovirus infection had elevated mean $\pm \mathrm{SE}$ levels of classical Th2 cytokines compared with individuals without detectable virus (IL-4: $8.1 \pm 0.8 \mathrm{pg} \cdot \mathrm{mL}^{-1}$ versus $4.1 \pm 0.5 \mathrm{pg} \cdot \mathrm{mL}^{-1}$; and IL-13: $10.2 \pm 1.5 \mathrm{pg} \cdot \mathrm{mL}^{-1}$ versus $\left.5.3 \pm \mathrm{SE} 0.9 \mathrm{pg} \cdot \mathrm{mL}^{-1}\right)$. Although rhinovirus also elicited Th1 antiviral responses, as demonstrated by higher IL-12 and IFN- $\gamma$ protein levels in rhinovirus-infected subjects relative to those with a negative viral PCR panel (mean \pm SE IL-12: $5.6 \pm 0.5 \mathrm{pg} \cdot \mathrm{mL}^{-1}$ versus $3.6 \pm 0.3 \mathrm{pg} \cdot \mathrm{mL}^{-1}$; and IFN- $\gamma: 8.3 \pm 1.5 \mathrm{pg} \cdot \mathrm{mL}^{-1}$ versus $3.8 \pm 0.7 \mathrm{pg} \cdot \mathrm{mL}^{-1}$; all $\mathrm{p}<0.05$ ) (figs $1 \mathrm{~d}$ and e), there was an overall predominance of Th2 cytokine production in the rhinovirus group according to Th2/Th1 cytokine ratio (IL-4/IL-12 ratio; 95\% CI 1.28-1.63 in rhinovirus versus $95 \%$ CI $0.99-1.26$ in control; $p=0.004$ ) (fig. 1f). Moreover, TSLP levels showed a moderate positive correlation with the Th2/Th1 cytokine ratio in rhinovirus-infected children $(r=0.37$; $\mathrm{p}<0.05$; fig. $1 \mathrm{~g}$ ). Collectively, our results indicate that acute rhinovirus infection during early childhood is associated with an enhanced airway secretion of TSLP/Th2 cytokines that predominates over Th1 antiviral nasal cytokine responses.

The nasal airway immune profile observed in young children infected with rhinovirus resembles what is seen in the lower airways of asthmatic individuals. Epithelial and sub-mucosal bronchial samples from adult asthmatic patients have enhanced TSLP mRNA expression, and bronchoalveolar lavage samples from these patients have higher concentrations of TSLP protein compared with those seen in healthy control subjects [6]. HBEC obtained from adult asthmatics exhibit a disproportionately high expression of TSLP relative to antiviral IFN- $\beta$ responses after exposure to dsRNA (rhinovirus mimic) [7]. Human nasal epithelial cells also produce TSLP after dsRNA exposure [8], suggesting that they are the potential origin of nasal TSLP in our study. However, TSLP is secreted by nasal fibroblasts as well [9], thus the specific cellular source and corresponding signalling mechanism mediating nasal TSLP secretion during rhinovirus infection in early life is still unclear. Nonetheless, the presented findings suggest that rhinovirus might promote pro-asthmatic changes in early life via enhanced airway TSLP levels, which are known to orchestrate Th2 atopic responses in the asthmatic lung $[3,10,11]$.

Our data also provides new evidence that viral respiratory illnesses in young children are associated with Th2 airway inflammation, which may explain why viruses such as rhinovirus elicit wheezing in early life, a clinical picture that resembles the asthmatic phenotype of older individuals [12, 13]. This has been suggested by a recent longitudinal study that reported that episodes of viral-induced wheeze in preschool children are characterised by enhanced airway inflammation (assessed by exhaled nitric oxide), reversible airflow limitation in spirometry, and asthma-related symptoms [14]. Our current preliminary work has not yet examined if the presence of elevated nasal TSLP and associated Th2 cytokines correlates with disease severity and/or predicts recurrence of the wheezing episodes. Nonetheless, recent reports suggest that the combination of a positive asthma predictive index with ongoing airway inflammation correlates with recurrent wheezing in young children [15]. This information highlights the importance of conducting future studies to investigate the potential role of airway pro-asthmatic biomarkers (i.e. TSLP and Th2 nasal cytokines) to better stratify viral-induced wheezing during preschool years and, thus, rationalise the use of asthma therapies in this age group.

In summary, our cross-sectional preliminary data indicate that acute rhinovirus infection in young children is associated with elevated nasal airway levels of TSLP/Th2 cytokines. This new information suggests that rhinovirus might shift immune responses towards Th2 in early life, which may facilitate the development of asthma during the first 3 years of life. However, given the cross-sectional design of our current study, we cannot prove a cause-effect relationship between rhinovirus infection, TSLP/Th2 responses and potential downstream effects resulting in pro-asthmatic effects later in life, thus, caution needs to be taken when interpreting the potential implications of these preliminary findings. Longitudinal studies are required to enhance our knowledge about the developmental aspects of TSLP biology and rhinovirus-induced Th2 

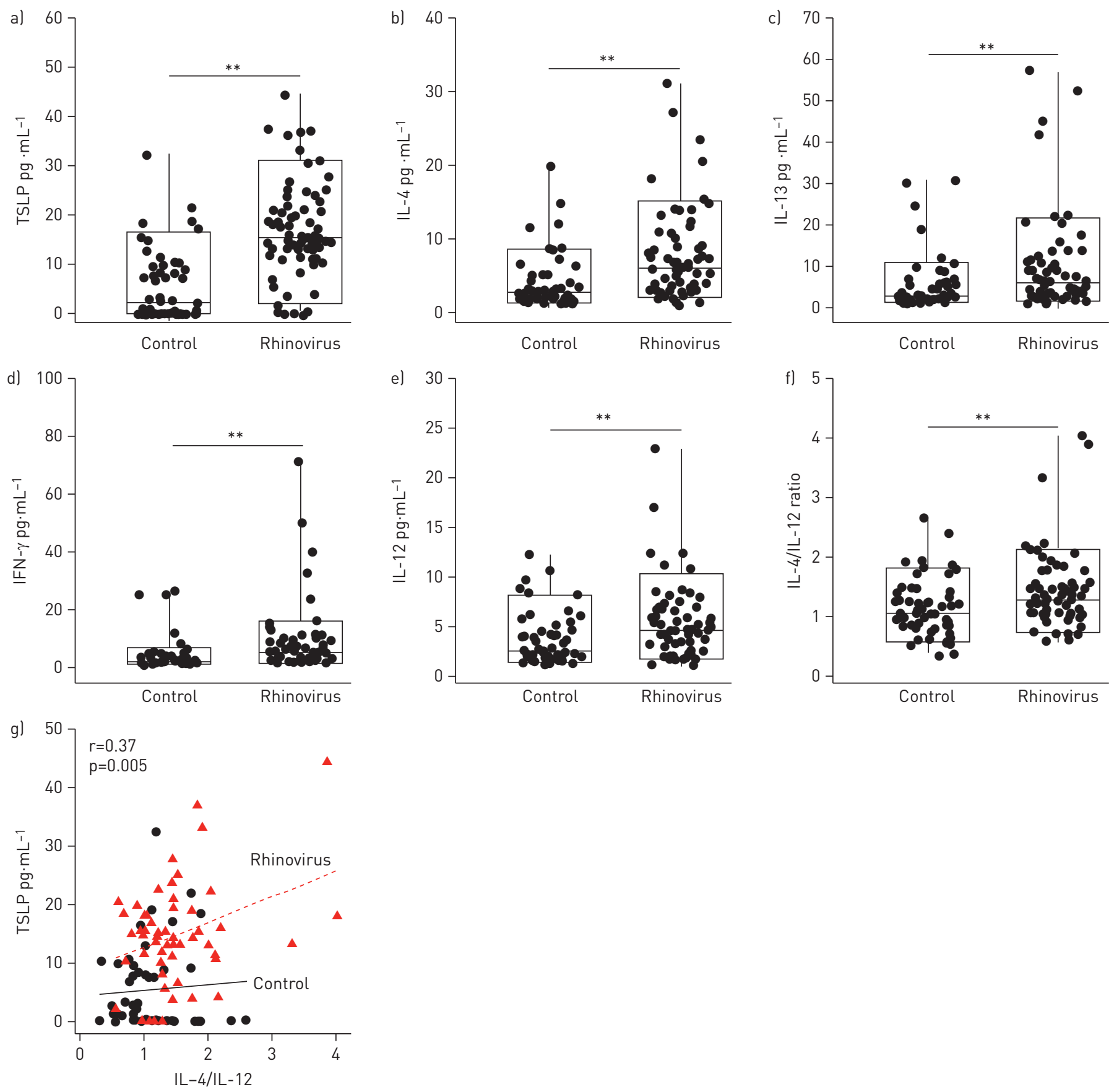

FIGURE 1 Nasal airway protein levels of a) thymic stromal lymphopoietin (TSLP), the T-helper cell (Th)2 cytokines b) interleukin (IL)-4 and c) IL-13, and the Th1 cytokines d) interferon (IFN)- $\gamma$ and e) IL-12. f) Th2/Th1 cytokine ratio (IL-4/IL-12) in subjects with rhinovirus relative to control. Data are presented as boxplots (boxes represent the median and interquartile range, and whiskers represent the 10th-90th percentile) and p-values were obtained by two-sample t-tests. ${ }^{* *}: \mathrm{p}<0.01$. g) Moderate positive linear relationship between TSLP and Th2/Th1 cytokine ratio (IL-4/IL-12) in subjects with rhinovirus ( $\mathrm{r}=$ Pearson correlation).

airway inflammation, which might ultimately lead to novel strategies for the management of viral-induced wheezing and childhood asthma.

@ERSpublications

Rhinovirus infection in young children is associated with elevated TSLP and Th2 cytokine nasal airway levels http://ow.ly/wZPSb

Geovanny F. Perez ${ }^{1}$, Krishna Pancham ${ }^{1}$, Shehlanoor Huseni ${ }^{1}$, Diego Preciado ${ }^{2,3,4,5}$, Robert J. Freishtat ${ }^{2,3,4,6}$, Anamaris M. Colberg-Poley ${ }^{2,3,4,7}$, Eric P. Hoffman ${ }^{2,3,4}$, Mary C. Rose ${ }^{1,2,3,4}$ and Gustavo Nino ${ }^{1,2,3,4}$ 
${ }^{1}$ Division of Pulmonary and Sleep Medicine, Children's National Medical Center, Washington, DC, USA. ${ }^{2}$ Dept of Pediatrics, George Washington University School of Medicine and Health Sciences, Washington, DC, USA. ${ }^{3}$ Dept of Integrative Systems Biology, George Washington University, Washington, DC, USA. ${ }^{4}$ Center for Genetic Research Medicine, Children's National Medical Center, Washington, DC, USA. ${ }^{5}$ Division of Pediatric Otorhinolaryngology, Depts of Surgery and Pediatrics, George Washington University School of Medicine and Health Sciences, Washington, DC, USA. 'Division of Emergency Medicine, Dept of Pediatrics, George Washington University School of Medicine and Health Sciences, Washington, DC, USA. ${ }^{7}$ Dept of Biochemistry and Molecular Medicine, George Washington University, Washington, DC, USA.

Correspondence: Gustavo Nino, Division of Pediatric Pulmonology and Sleep Medicine, Children's National Medical Center, Center for Genetic Medicine Research, 111 Michigan Avenue, NW, Washington, DC 20010, USA.

E-mail: gnino@childrensnational.org

Received: March 132014 | Accepted after revision: May 122014 | First published online: June 252014

Support statement: This study was supported by NIH grants HL090020, HD001399 and the Board of Visitors (BOV) grant of Children's National Medical Center.

Conflict of interest: None declared.

\section{References}

Lemanske RF Jr, Jackson DJ, Gangnon RE, et al. Rhinovirus illnesses during infancy predict subsequent childhood wheezing. J Allergy Clin Immunol 2005; 116: 571-577.

2 Schneider D, Hong JY, Popova AP, et al. Neonatal rhinovirus infection induces mucous metaplasia and airways hyperresponsiveness. J Immunol 2012; 188: 2894-2904.

Ziegler SF, Artis D. Sensing the outside world: TSLP regulates barrier immunity. Nat Immunol 2010; 11: 289-293. Mahmutovic-Persson I, Akbarshahi H, Bartlett NW, et al. Inhaled dsRNA and rhinovirus evoke neutrophilic exacerbation and lung expression of thymic stromal lymphopoietin in allergic mice with established experimental asthma. Allergy 2014; 69: 348-358.

5 Kato A, Favoreto S Jr, Avila PC, et al. TLR3- and Th2 cytokine-dependent production of thymic stromal lymphopoietin in human airway epithelial cells. J Immunol 2007; 179: 1080-1087.

6 Ying S, O'Connor B, Ratoff J, et al. Thymic stromal lymphopoietin expression is increased in asthmatic airways and correlates with expression of Th2-attracting chemokines and disease severity. J Immunol 2005; 174: 8183-8190.

7 Uller L, Leino M, Bedke N, et al. Double-stranded RNA induces disproportionate expression of thymic stromal lymphopoietin versus interferon- $\beta$ in bronchial epithelial cells from donors with asthma. Thorax 2010; 65: 626-632.

8 Fuchimoto J, Kojima T, Kobayashi N, et al. Hop water extract inhibits double-stranded RNA-induced thymic stromal lymphopoietin release from human nasal epithelial cells. Am J Rhinol Allergy 2012; 26: 433-438.

9 Nonaka M, Fukumoto A, Ogihara N, et al. Synergistic induction of thymic stromal lymphopoietin by tumor necrosis factor $\alpha$ and Th2 cytokine in nasal polyp fibroblasts. Am J Rhinol Allergy 2010; 24: e14-e18.

10 Cheng DT, Ma C, Niewoehner J, et al. Thymic stromal lymphopoietin receptor blockade reduces allergic inflammation in a cynomolgus monkey model of asthma. J Allergy Clin Immunol 2013; 132: 455-462.

11 Han H, Headley MB, Xu W, et al. Thymic stromal lymphopoietin amplifies the differentiation of alternatively activated macrophages. J Immunol 2013; 190: 904-912.

12 Zhu J, Message SD, Qiu Y, et al. Airway inflammation and illness severity in response to experimental rhinovirus infection in asthma. Chest 2014; 145: 1219-1229.

13 Message SD, Laza-Stanca V, Mallia P, et al. Rhinovirus-induced lower respiratory illness is increased in asthma and related to virus load and Th1/2 cytokine and IL-10 production. Proc Natl Acad Sci USA 2008; 105: 13562-13567.

14 Konstantinou GN, Xepapadaki P, Manousakis E, et al. Assessment of airflow limitation, airway inflammation, and symptoms during virus-induced wheezing episodes in 4- to 6-year-old children. J Allergy Clin Immunol 2013; 131: 87-93.

15 Castro-Rodriguez JA, Molina RO, Cáceres M, et al. Correlation between nitrites in induced sputum and asthma symptoms in asthmatic school children. Pediatr Pulmonol 2014; 49: 214-220.

\section{Increased prevalence of pre-school wheeze is not explained by time trends in body mass index}

To the Editor:

Overweight and obesity have been associated with asthma, particularly in adults [1-4]. In children, findings are less consistent $[2,5-7]$. Different mechanisms have been proposed to explain this association, including lung mechanics, systemic inflammation and associated comorbidities $[1,2,8]$. In a previous study, we 